\title{
Bullying behaviour and psychosocial health among school students in New South Wales, Australia: cross sectional survey
}

\author{
Roberto Forero, Lyndall McLellan, Chris Rissel, Adrian Bauman
}

\begin{abstract}
Editorial by
Chesson and p 348

Health Promotion

Unit, Liverpool

Hospital, Liverpool,

New South Wales

2070, Australia

Roberto Forero,

research and

evaluation

coordinator

Needs Assessment and Health

Outcomes Unit,

Central Sydney

Area Health

Service, Newtown,

New South Wales

2042, Australia

Lyndall McLellan,

project officer

Chris Rissel,

epidemiologist

School of

Community

Medicine,

University of New

South Wales,

Kensington, New

South Wales 2052,

Australia

Adrian Bauman,

professor of public

health

Correspondence to:

C Rissel

criss@nah.rpa

cs.nsw.gov.au
\end{abstract}

BMJ 1999;319:344-8

\begin{abstract}
Objectives To examine the prevalence of bullying behaviours in schoolchildren and the association of bullying with psychological and psychosomatic health.

Design Cross sectional survey.

Setting Government and non-government schools in New South Wales, Australia.

Participants 3918 schoolchildren attending year 6 (mean age 11.88 years), year 8 (13.96), and year 10 (15.97) classes from 115 schools.

Main outcome measures Self reported bullying behaviours and psychological and psychosomatic symptoms.

Results Almost a quarter of students (23.7\%) bullied other students, $12.7 \%$ were bullied, $21.5 \%$ were both bullied and bullied others on one or more occasions in the last term of school, and $42.4 \%$ were neither bullied nor bullied others. More boys than girls reported bullying others and being victims of bullying. Bullying behaviour was associated with increased psychosomatic symptoms. Bullies tended to be unhappy with school; students who were bullied tended to like school and to feel alone. Students who both bullied and were bullied had the greatest number of psychological and psychosomatic symptoms.

Conclusions Being bullied seems to be widespread in schools in New South Wales and is associated with increased psychosomatic symptoms and poor mental health. Health practitioners evaluating students with common psychological and psychosomatic symptoms should consider bullying and the student's school environment as potential causes.
\end{abstract}

\section{Introduction}

Recent reports have highlighted the frequency of bullying in schools and the adverse consequences on bullying behaviour in adolescence. ${ }^{1-7}$ Despite the efforts of schools to prevent or stop bullying, it still occurs worldwide. ${ }^{28-10}$ Victims of frequent bullying have been reported to experience a range of psychological, psychosomatic, and behavioural symptoms including anxiety and insecurity, ${ }^{11}$ low self esteem and low self worth, ${ }^{312}$ considerable mental health problems, sleeping difficulties, bed wetting, feelings of sadness, and frequent headaches and abdominal pain. ${ }^{15}$ They are also more likely to be unhappy and depressed ${ }^{5}$ and absent from school. ${ }^{13}$

Although definitions of bullying behaviour vary, bullying has been defined as the "intentional, unprovoked abuse of power by one or more children to inflict pain or cause distress to another child on repeated occasions." ${ }^{14}$ The most common form of bullying self reported by Australian students is verbal harassment-for example, teasing and name calling. ${ }^{13}$
This is consistent with students in Norway ${ }^{15}$ and England. ${ }^{1}$ Most students do nothing to help victims because they feel it is not their place to get involved..$^{16} 17$

Reported estimates of bullying vary owing to differences in the type of measurements taken and the sex, age, and ethnic origin of students studied. For example, in Newham, east London, 22\% of young people had been bullied at some time. ${ }^{1}$ In Yorkshire, $21 \%$ of children had been bullied and about $17 \%$ had taken part in bullying others "sometimes or more often." ${ }^{18}$ Another study in the United Kingdom found these rates to be $4.2 \%$ and $3.4 \%$ respectively. ${ }^{11}$ The weekly incidence of bullying in Australian schools has been estimated at about 1 in 6 children during any one year. ${ }^{16}$ Bullying has been found to decrease with age, with boys more likely to have been bullied and to participate in bullying others compared with girls. ${ }^{511} 1318$ Bullies are more likely to dislike school and to engage in behaviours that compromise their health such as smoking and drinking alcohol to excess. ${ }^{5}$ According to the problem behaviour theory, bullying others may be one of a cluster of problem behaviours. ${ }^{19}$

Our study sought to identify the prevalence of bullying behaviours among schoolchildren in New South Wales, Australia, and the association of bullying with psychological and psychosomatic health. Our study differs from earlier ones by differentiating students involved in bullying behaviour from those who bully and are themselves bullied, those who only bully, those who are only bullied, and those who are neither bullies nor bullied.

\section{Participants and methods}

\section{Participants}

Analyses are based on a statewide sample of year 6 (primary) and year 8 and year 10 (secondary) students attending one of 115 Catholic, government, and independent schools. We stratified the schools into primary and secondary schools, and we selected those to participate through cluster random sampling defined by school class.

Participation was voluntary and anonymous. We obtained ethical approval for our study from the relevant education sectors and the New South Wales Health Department.

\section{Methods}

We randomly selected one class from each selected school year according to the World Health Organisation's survey protocol for health behaviour among schoolchildren. ${ }^{5}$ The self administered surveys were completed in classrooms under exam-like conditions in October and November 1996, at the end of the last term (term 3) of the Australian school calendar. 
Survey methods

The survey was administered statewide by health promotion staff of the New South Wales Health Department. The questionnaire was adapted ${ }^{20}$ from the WHO's health behaviour survey in schoolchildren, which has been shown to be valid and reliable in Europe for over a decade. ${ }^{5}$ The core questionnaire was validated for Australian conditions in 1992 and $1996 .^{20}$ Questions from the instrument that are the focus of our report relate to demographics, bullying, psychosomatic symptoms, mental health, and school and social contact.

\section{Categorisation of bullying behaviours}

Bullying behaviours were the dependent variables. We used the following definition: "Bullying is when another student, or group of students, says or does nasty and unpleasant things to him or her. It is also bullying when a student is teased repeatedly in a way he or she doesn't like. But it is not bullying when two students about the same strength quarrel or fight." Students were asked to respond to two questions: have you ever been bullied in school this term? and, how often have you taken part in bullying other students in school this term? We dichotomised responses into students who had not experienced bullying behaviour or who had (once or more). We then further classified the students into four groups as bullies, bullied, both bullies and bullied, and neither bullies nor bullied.

\section{Psychosomatic symptoms}

Students were presented with a series of health symptoms (headache, stomach ache, backache, feeling low, irritable or bad temper, feeling nervous, difficulties getting to sleep, feeling dizzy) and asked to report the frequency with which they experienced each. These items were summed to form a unit weighted psychosomatic symptom scale, and frequency of symptoms was categorised as: low scores (0-4; up to three symptoms less than once a month or never); moderate (5-8; four or more symptoms about every month or up to three per week); frequent (9-14; four or more symptoms once per week or up to three per week); and high (1532 ; four or more symptoms more than once a week or about every day) (mean 8.5 (SD 6.3)). The Cronbach's $\alpha$ of the scale was 0.81 .

\section{Dichotomised responses}

Smoking-Current smoking was identified by asking the students how often they smoked at present. We dichotomised responses as less than weekly and once or more per week.

Mental health-We examined four single items assessing dimensions of mental health. Happiness was assessed by asking the students how generally they felt about life at present (responses dichotomised as happy or unhappy). Loneliness was measured by asking the students if they ever felt lonely (responses dichotomised as lonely or not lonely). Students were then asked how often it happened (during the last school term) that other students did not want to spend time with them and they ended up being alone (responses dichotomised as alone or not alone). Confidence was measured by asking the students whether they felt confident in themselves (responses dichotomised as confident or not confident).
Social contact-We assessed social contact by asking the students how often they spent time with friends straight after school, and how many evenings per week they usually spent out with their friends. We dichotomised responses as frequent (four or more days and three or more evenings) or infrequent (three or less days and four or more evenings).

Reactions to school-To assess the students' reactions to school we asked three pertinent questions: how they felt about school at present (dichotomised into like or dislike); whether school was a nice place to be (dichotomised into agree or disagree); and absenteeism (whole days) during the past four weeks of school without parental permission ("wagging") before the survey was administered (dichotomised as frequent or infrequent).

\section{Statistical analysis}

We assessed the prevalence of the studied items by sex and school year with descriptive univariate statistics produced by SPSS release 6 software. The selected independent variables were dichotomised as healthy and non-healthy, and we examined their associations with bullying behaviours.

We used STATA software (release 5) to test the associations between the independent and dependent variables, adjusting for the design effect of clustering within schools. For this analysis we have assumed that there were four different bullying outcomes. In this case bullying outcomes were unordered events.

Multinomial logistic regression (STATA; College Station, TX) is an extension to the usual model for binary data ${ }^{21}$ and is used to model an outcome that is measured on a nominal scale (no natural order). We

Table 1 Unadjusted prevalence of bullying behaviour and health symptoms in 3918 students from schools in New South Wales

\begin{tabular}{|c|c|c|c|c|c|c|}
\hline \multirow[b]{2}{*}{ Variable } & \multicolumn{2}{|c|}{ Year 6} & \multicolumn{2}{|c|}{ Year 8} & \multicolumn{2}{|c|}{ Year 10} \\
\hline & $\begin{array}{c}\text { Boys } \\
(n=642)\end{array}$ & $\begin{array}{c}\text { Girls } \\
(n=580)\end{array}$ & $\begin{array}{c}\text { Boys } \\
(n=593)\end{array}$ & $\begin{array}{c}\text { Girls } \\
(\mathrm{n}=810)\end{array}$ & $\begin{array}{c}\text { Boys } \\
(n=529)\end{array}$ & $\begin{array}{c}\text { Girls } \\
(\mathrm{n}=739)\end{array}$ \\
\hline \multicolumn{7}{|l|}{ Bullying behaviour } \\
\hline Neither bullied nor bully & 34.1 & 44.8 & 26.5 & 45.9 & 36.1 & 61.0 \\
\hline Bullied & 11.5 & 18.1 & 15.5 & 13.3 & 8.5 & 9.9 \\
\hline Bully & 28.5 & 17.6 & 27.5 & 21.4 & 34.0 & 17.2 \\
\hline Both bullied and bully & 25.9 & 19.5 & 30.5 & 19.4 & 21.4 & 11.9 \\
\hline \multicolumn{7}{|l|}{ Psychosomatic symptoms (scores)* } \\
\hline Low $(0-4)$ & 35.1 & 35.4 & 35.8 & 27.2 & 31.7 & 21.3 \\
\hline Moderate (5-8) & 27.4 & 25.7 & 28.8 & 26.1 & 31.9 & 28.4 \\
\hline Frequent (9-14) & 25.7 & 23.6 & 21.9 & 26.0 & 23.4 & 28.1 \\
\hline High (15-32) & 11.8 & 15.2 & 13.5 & 20.7 & 13.1 & 22.3 \\
\hline \multicolumn{7}{|l|}{ Mental health } \\
\hline Unhappy & 7.7 & 6.9 & 14.1 & 16.3 & 7.6 & 13.8 \\
\hline Lonely & 9.4 & 12.8 & 12.2 & 14.7 & 12.5 & 21.2 \\
\hline \multicolumn{7}{|l|}{ Social contact } \\
\hline Ostracised & 5.6 & 8.4 & 5.6 & 4.1 & 3.8 & 2.4 \\
\hline$\leqslant 2$ evenings with friends & 68.0 & 79.0 & 69.0 & 75.3 & 75.0 & 76.7 \\
\hline$\leqslant 3$ days with friends after school & 57.2 & 67.9 & 59.2 & 72.5 & 63.3 & 74.7 \\
\hline \multicolumn{7}{|l|}{ Risk behaviour } \\
\hline $\begin{array}{l}\text { Current smoking (weekly or more } \\
\text { often) }\end{array}$ & 3.7 & 2.4 & 11.9 & 11.6 & 15.9 & 17.1 \\
\hline \multicolumn{7}{|l|}{ Reactions to school } \\
\hline Dislike school & 33.8 & 18.1 & 43.8 & 31.5 & 32.4 & 29.9 \\
\hline School is not nice place to be & 40.2 & 24.0 & 62.3 & 60.8 & 63.0 & 56.4 \\
\hline Frequent absence without permission & 3.0 & 0.7 & 5.8 & 2.4 & 5.3 & 2.5 \\
\hline
\end{tabular}

${ }^{*} 0-4$ : up to 3 symptoms less than once a month or never; 5-8: 4 or more symptoms about every month or up to 3 per week; 9-14: 4 or more symptoms once per week or up to 3 per week; 15-32: 4 or more symptoms more than once a week or about every day. 
Table 2 Multinominal logistic regression analysis of bullying behaviour in 3918 students in schools in New South Wales. Comparison group was 1650 students who neither were bullied nor bully

\begin{tabular}{|c|c|c|c|c|c|c|c|c|c|}
\hline \multirow[b]{2}{*}{ Characteristics } & \multicolumn{3}{|c|}{ Students who bully ( $\mathrm{n}=928$ ) } & \multicolumn{3}{|c|}{ Bullied students ( $n=497$ ) } & \multicolumn{3}{|c|}{ Bullied students who bully ( $n=818$ ) } \\
\hline & $\begin{array}{l}\text { Relative risk ratio } \\
(95 \% \mathrm{Cl})\end{array}$ & SE & $P$ value & $\begin{array}{c}\text { Relative risk ratio } \\
(95 \% \mathrm{Cl})\end{array}$ & SE & $P$ value & $\begin{array}{c}\text { Relative risk ratio } \\
(95 \% \mathrm{Cl})\end{array}$ & SE & $P$ value \\
\hline \multicolumn{10}{|l|}{$\operatorname{Sex}^{*}$} \\
\hline$\overline{\text { Female }}$ & 1.0 & & & 1.0 & & & 1.0 & & \\
\hline Male & 2.0 (1.61 to 2.51$)$ & 0.22 & $<0.05$ & 1.25 (0.97 to 1.58$)$ & 0.15 & NS & 2.07 (1.64 to 2.63$)$ & 0.25 & $<0.05$ \\
\hline \multicolumn{10}{|l|}{ School class } \\
\hline Year 6 & 1.0 & & & 1.0 & & & 1.0 & & \\
\hline 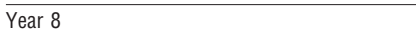 & 0.65 (0.47 to 0.90$)$ & 0.11 & $<0.05$ & 0.71 (0.52 to 0.98$)$ & 0.11 & $<0.05$ & 0.65 (0.45 to 0.93$)$ & 0.12 & $<0.05$ \\
\hline Year 10 & $0.48(0.36$ to 0.69$)$ & 0.08 & $<0.05$ & $0.32(0.22$ to 0.45$)$ & 0.06 & $<0.05$ & 0.28 (0.21 to 0.39$)$ & 0.05 & $<0.05$ \\
\hline \multicolumn{10}{|l|}{$\begin{array}{l}\text { Psychosomatic symptom scale (scores) } \dagger \\
\end{array}$} \\
\hline Low (0-4) & 1.0 & & & 1.0 & & & 1.0 & & \\
\hline Moderate (5-8) & 1.28 (0.99 to 1.63$)$ & 0.16 & NS & 0.91 (0.69 to 1.22$)$ & 0.13 & NS & 1.17 (0.87 to 1.57$)$ & 0.17 & NS \\
\hline Frequent (9-14) & 1.61 (1.20 to 2.17 ) & 0.24 & $<0.05$ & 0.96 (0.73 to 1.27$)$ & 0.13 & NS & 1.63 (1.23 to 2.17$)$ & 0.23 & $<0.05$ \\
\hline High (15-32) & 1.80 (1.21 to 2.65$)$ & 0.36 & $<0.05$ & $1.11(0.72$ to 1.70$)$ & 0.24 & NS & 1.97 (1.37 to 2.81$)$ & 0.35 & $<0.05$ \\
\hline \multicolumn{10}{|l|}{ Mental health } \\
\hline Happy & 1.0 & & & 1.0 & & & 1.0 & & \\
\hline Unhappy & 0.80 (0.54 to 1.18$)$ & 0.16 & NS & 1.40 (0.83 to 2.34$)$ & 0.36 & NS & 0.79 (0.52 to 1.19$)$ & 0.16 & NS \\
\hline Not lonely & 1.0 & & & 1.0 & & & 1.0 & & \\
\hline Lonely & 0.76 (0.53 to 1.09$)$ & 0.14 & NS & $1.72(1.19$ to 2.51$)$ & 0.33 & $<0.05$ & $1.23(0.88$ to 1.71$)$ & 0.20 & NS \\
\hline \multicolumn{10}{|l|}{ Social contact } \\
\hline Not alone & 1.0 & & & 1.0 & & & 1.0 & & \\
\hline Ostracised & $0.74(0.37$ to 1.48$)$ & 0.26 & NS & 3.40 (1.82 to 6.35$)$ & 1.07 & $<0.05$ & 2.45 (1.32 to 4.53$)$ & 0.76 & $<0.05$ \\
\hline$\leqslant 3$ days spent with friends after school & 1.0 & & & 1.0 & & & 1.0 & & \\
\hline$\geqslant 4$ days spent with friends after school & 1.23 (0.99 to 1.53$)$ & 0.13 & NS & $0.87(0.65$ to 1.17$)$ & 0.13 & NS & 0.68 (0.51 to 0.90$)$ & 0.09 & $<0.05$ \\
\hline$\leqslant 2$ evenings out with friends & 1.0 & & & 1.0 & & & 1.0 & & \\
\hline$\geqslant 3$ evenings out with friends & $1.37(1.07$ to 1.71$)$ & 0.17 & $<0.05$ & $0.52(0.37$ to 0.72$)$ & 0.09 & $<0.05$ & $1.41(1.11$ to 1.80$)$ & 0.17 & $<0.05$ \\
\hline \multicolumn{10}{|l|}{ Risk behaviour } \\
\hline Non-smoker & 1.0 & & & 1.0 & & & 1.0 & & \\
\hline Current smoker & 1.50 (1.01 to 2.22$)$ & 0.30 & $<0.05$ & 0.38 (0.21 to 0.69$)$ & 0.11 & $<0.05$ & 1.81 (1.26 to 2.59$)$ & 0.32 & $<0.05$ \\
\hline \multicolumn{10}{|l|}{ Reactions to school } \\
\hline Dislike school & 1.0 & & & 1.0 & & & 1.0 & & \\
\hline Like school & 0.48 (0.37 to 0.63$)$ & 0.06 & $<0.05$ & $0.57(0.42$ to 0.76$)$ & 0.08 & $<0.05$ & $0.57(0.39$ to 0.65$)$ & 0.09 & $<0.05$ \\
\hline School is not nice place to be & 1.0 & & & 1.0 & & & 1.0 & & \\
\hline School is nice place to be & $0.55(0.43$ to 0.71$)$ & 0.07 & $<0.05$ & 0.69 (0.53 to 0.89$)$ & 0.09 & $<0.05$ & $0.50(0.39$ to 0.65$)$ & 0.07 & $<0.05$ \\
\hline$\leqslant 3$ days of school missed without permission & 1.0 & & & 1.0 & & & 1.0 & & \\
\hline$\geqslant 4$ days of school missed without permission & 1.51 (0.68 to 3.35$)$ & 0.61 & NS & 0.48 (0.11 to 2.03$)$ & 0.34 & NS & 1.02 (0.44 to 2.32$)$ & 0.42 & NS \\
\hline
\end{tabular}

*Unspecified in 25 students.

†0-4: up to 3 symptoms less than once a month or never; 5-8: 4 or more symptoms about every month or up to 3 per week; 9-14: 4 or more symptoms once per week or up to 3 per week; 15-32: 4 or more symptoms more than once a week or about every day.

used svymlog ${ }^{21}$ (STATA) to estimate the adjusted relative risk ratio of age, sex, psychosomatic symptoms, and sociodemographic factors on children from each of the bullying categories of bully, bullied, and "both" versus the comparison group "neither."

\section{Results}

Sample characteristics

Complete questionnaires were received from 3918 students-2129 girls (54.3\%), 1764 boys (45.0\%), and $25(0.64 \%)$ not specified-representing a participation rate of $84 \%$ on the basis of enrolment figures for secondary school years 8 and 10, and $88 \%$ for primary school year 6 . The mean age of our sample was 11.88 years (SD 0.52) for year 6 students, $13.96(0.54)$ years for year 8 students, and 15.97 (0.51) years for year 10 students. Boys and girls in each year were of identical age. Student distribution across the school years was similar: 1222 students in year $6(31.1 \%), 1403$ in year 8 (35.8\%), and 1268 in year 10 (32.4\%). Overall, 443 students $(11.3 \%)$ were born overseas, $3381(86.3 \%)$ were born in Australia, and 94 (2.4\%) were from an indigenous background.
Overall, 1650 students (42.4\%) reported neither being bullied nor bullying others in the last term of the school calendar. Of the remaining 2268 students (57.8\%), 928 (23.7\%) bullied others, 843 (21.5\%) both bullied and were bullied, and 497 (12.7\%) were bullied. More boys $(526,29.8 \%)$ than girls $(402,18.9 \%)$ reported bullying or both being bullied and bullying (460 boys (26.1\%), 358 girls (16.8\%)), but slightly more girls $(286,13.4 \%)$ than boys $(211,12.0 \%)$ reported being bullied.

\section{Prevalence of bullying behaviours}

Table 1 presents the unadjusted prevalence of bullying behaviours and the studied variables by school year and sex. Table 2 presents the results from the multinomial logistic regression of students who bullied, who were bullied, and who were both bullied and bullied others. We used the group of students who reported neither having been bullied nor bullying other students as the comparison group.

\section{Bullies}

After adjusting for survey sampling and the other social and psychological factors in our model, significantly more boys than girls were bullies (relative 
risk ratio 2.0); bullies experienced frequent (1.6) and high scores for psychosomatic symptoms (1.8), were current smokers (1.5), spent four days or more with friends after school (1.2), and spent three or more evenings out with friends (1.4). Bullies were significantly more likely to be in year 6 than years 8 or 10 (0.65 and 0.48 respectively), did not like school (0.48), and did not think that school was a nice place to be (0.55) (table 2).

\section{Bullied students}

Those who were bullied were more likely to be boys than girls (1.3), to be lonely (1.7), and to find themselves alone because other students did not want to spend time with them at school (3.4). Bullied students were less likely to be in year $8(0.71)$ or year $10(0.32)$, spent three or more evenings out with friends (0.52), did not like school (0.57), were current smokers (0.38), and missed days from school without permission from their parents (0.48) (table 2).

\section{Bullied students who also bullied}

Students who were both bullied and bullied others were significantly more likely to be boys (2.1), experienced frequent (1.6) and high scores for psychosomatic symptoms (2.0), reported being alone (2.5), were current smokers (1.8), and spent three or more evenings out with friends (1.4). These students were significantly less likely to be in year $8(0.65)$ or year 10 (0.28), to spend time with friends after school (0.68), to feel school was a nice place to be $(0.50)$, and to like school (0.57) (table 2).

\section{Discussion}

Our results indicate that, in one term of the school year, more than three out of five students experienced or participated in bullying in schools in New South Wales. The estimate of $13 \%$ of students as victims of bullying is less than that reported in English schools, although this number increased substantially to $34 \%$ when we included students who both bullied and were bullied. Exposure to bullying may be substantial for those who are bullied as there were more students who bullied (but not also bullied) than students who were bullied.

Our results show a statistically significant association between bullying behaviour and psychosomatic symptoms and smoking, with those students who both bullied and were bullied reporting the highest frequency of symptoms. Bullies tended to be unhappy with school, and students who were bullied tended to like school more and to report feeling alone. Unsurprisingly, students who both bullied and were bullied exhibited the characteristics of disliking school and feeling alone, and they seemed to have the most psychological and psychosomatic symptoms.

Although our results are cross sectional, they are consistent with other findings that have identified bullied children as having few friends, being more introverted than others, and generally lacking social skills. ${ }^{213}$ Bullies also deserve attention. Dawkins says that bullying may be one component of a more general pattern of antisocial and rule breaking behaviour that shows considerable stability over time, ${ }^{14}$ although our data do not address this point.
Key messages

- Bullying behaviour occurs in schools worldwide and is likely to be associated with poor health in schoolchildren

- Research into bullying has been mainly focused on victims but there are other categories of bullying that deserve attention

- At least three out of five students experienced or participated in bullying in schools in New South Wales, Australia

- The psychosocial and psychosomatic health of the students varied according to their bullying status

As suggested by others, ${ }^{14}$ health practitioners evaluating students with common psychological and psychosomatic symptoms should consider bullying and the student's school environment as a potential cause. A positive school environment may increase health promoting behaviours ${ }^{122}$ and it is likely that bullying and its consequences can be reduced if the school does not tolerate bullying. Engaging the assistance of children not involved in bullying may help to reduce tolerance of bullying and change the normal attitudes around bullying. Studies of policies and strategies that effectively reduce bullying are needed.

We thank all the schools, staff, and students who participated, the health promotion staff throughout New South Wales who assisted with data collection, and Ms Philayrath Phonsavan, who coordinated the data management.

Contributors: $\mathrm{AB}$ and $\mathrm{LM}$ initiated the study, designed the protocol and materials, collected and collated the data, and carried out reference study No 20. RF developed the model and conducted the multinomial logistic regression analysis. LM conducted univariate data analysis. $\mathrm{RF}, \mathrm{LM}, \mathrm{CR}$, and $\mathrm{AB}$ interpreted the results, discussed their meaning, and contributed to the writing and editing of this manuscript. CR and RF contributed to reference study No $20 \mathrm{AB}$ will act as guarantor for the paper.

Funding: Epidemiology Unit, South Western Sydney Area Health Service. The health promotion branch of the New South Wales Health Department provided a small grant for the printing of the surveys.

Competing interests: None declared.

1 Williams K, Chambers M, Logan S, Robinson D. Association of common health symptoms with bullying in primary schoolchildren. BMJ 1996;313:17-9.

2 Rigby K, Slee PT. Dimensions of interpersonal relating among Australian schoolchildren and their implications for psychological well-being. J Soc Psychol 1993;133:33-42.

3 Boulton MJ, Smith PK. Bully/victim problems among middle school children: stability, self perceived competence, and peer acceptance. $\mathrm{Br} J$ Dev Psychol 1994;12:315-29.

4 Mynard H, Joseph S. Bully/victim problems and their association with Eysenck's personality dimensions in 8- to 13-year-olds. Br J Educ Psychol 1997;67:51-4.

5 King A, Wold B, Tudor-Smith C, Harel Y. The health of youth: a cross-national survey, 1996. (WHO Regional Publications, European Series No 69.)

6 Zubrick SR, Silburn SR, Gurrin L, Teoh H, Shepherd C, Carlton J, et al. Western Australian child health survey:education, health and competence. Perth, WA: Australian Bureau of Statistics and Institute for Child Health Research, 1997.

7 Olweus D. Bullying at school: basic facts and an effective intervention programme. J Child Psychol Psychiatry Allied Disciplines 1994;35:1171-90.

8 Smith PK, Sharp S. School bullying: insights and perspectives. London: Routledge, 1994

9 Oliver R. Family issues of interventions in bully and victim relationships. Sch Counsellor 1994;41:199-202.

10 Neary A. Peer victimization and its relationship to self-concept and depression among school girls. Pers Individual Differences 1994;16:183-6.

11 Salmon G, James A, Smith DM. Bullying in schools: self reported anxiety, depression, and self esteem in secondary school children. BMJ 1998;317:924-5 
12 Rigby K. Peer relations at school and the health of adolescents. Youth Stud Aust 1998; 17:13-7.

13 Rigby K. What children tell us about bullying in schools. Child Aust 1997;22:28-34.

14 Dawkins J. Bullying in schools: doctors' responsibilities. BMJ 1995;310:274-5.

15 Olweus D. Bullying at school. Oxford: Blackwell, 1993

16 Rigby K. Bullying in Australian schools-and what to do about it. Melbourne, NSW: Australian Council for Educational Research, 1996.

17 Whitney I, Smith PK. A survey of the nature and extent of bullying in junior/middle and secondary schools. Educ Res 1993;35:3-25.

18 Boulton MJ, Underwood K. Bully/victim problems among middle school children. Br J Educ Psychol 1992;62:73-87.
19 Jessor R, Jessor SL. Problem behaviour and psychosocial development. A long itudinal study of youth. New York: Academic, 1977.

20 Bauman A, Hogan A, McLellan L, Rissel C, Mayne D, Gill L, et al. Health behaviours of New South Wales school students:report of the NSW health behaviour of school students (NSW HBSS) survey, 1996. Sydney, NSW: National Centre for Health Promotion, 1998.

21 Eltinge JL, Sribney WM. Versions of mlogit, ologit, and oprobit for survey data. Stata Stat Bull 1997:40:39-42.

22 Nutbeam D, Smith C, Moore L, Bauman A. Warning! Schools can damage your health: alienation from school and its impact on behaviour. J Paediatr Child Health 1993;29(suppl.1):25-30S.

(Accepted 4 May 1999)

\title{
Bullying, depression, and suicidal ideation in Finnish adolescents: school survey
}

\author{
Riittakerttu Kaltiala-Heino, Matti Rimpelä, Mauri Marttunen, Arja Rimpelä, Päivi Rantanen
}

\section{Editorial by \\ Chesson and p 344 \\ University of \\ Tampere, Tampere \\ School of Public \\ Health, Box 607, \\ 33101 Tampere, \\ Finland \\ Riittakerttu \\ Kaltiala-Heino \\ senior assistant \\ professor \\ Arja Rimpelä \\ professor \\ National Research and Development \\ Centre for Welfare \\ and Health, \\ Box 220, 00531 \\ Helsinki, Finland \\ Matti Rimpelä \\ professor \\ Department of \\ Mental Health and \\ Alcohol Research, \\ National Public \\ Health Institute, \\ Mannerheimintie \\ 166, 00300 Helsinki \\ Mauri Marttunen \\ senior researcher \\ Tampere University Hospital, \\ Department of \\ Adolescent \\ Psychiatry, \\ Box 2000, \\ 33521 Tampere \\ Päivi Rantanen \\ professor}

Correspondence to:

R Kaltiala-Heino

merihe@uta.fi

BMJ 1999;319:348-51

\begin{abstract}
Objective To assess the relation between being bullied or being a bully at school, depression, and severe suicidal ideation.

Design A school based survey of health, health behaviour, and behaviour in school which included questions about bullying and the Beck depression inventory, which includes items asking about suicidal ideation.

Setting Secondary schools in two regions of Finland. Participants 16410 adolescents aged 14-16.

Results There was an increased prevalence of depression and severe suicidal ideation among both those who were bullied and those who were bullies. Depression was equally likely to occur among those who were bullied and those who were bullies. It was most common among those students who were both bullied by others and who were also bullies themselves. When symptoms of depression were controlled for, suicidal ideation occurred most often among adolescents who were bullies.

Conclusion Adolescents who are being bullied and those who are bullies are at an increased risk of depression and suicide. The need for psychiatric intervention should be considered not only for victims of bullying but also for bullies.
\end{abstract}

\section{Introduction}

About 1 in 10 schoolchildren report being bullied weekly at school. ${ }^{1-4}$ Boys are involved in bullying, both as victims and as bullies, more often than girls. Primary school children are more likely to be victims of bullying than adolescents, but the number of bullies tends to remain constant between primary school and secondary school. ${ }^{2} 3$

The possible association between being bullied and the risk of suicide has been recognised by adolescent psychiatrists, ${ }^{5}$ but epidemiological studies have not assessed the correlation. Salmon et al found an association between being bullied and being depressed. ${ }^{6}$ In children, being bullied has been associated with an increase in psychological and psychosomatic symptoms. Williams et al found that children who were frequently bullied at school were more likely to wet their beds, have difficulty sleeping, and have headaches and abdominal pain. ${ }^{7}$ Kumpulainen et al found an association between involvement in bullying (being bullied or being a bully) and a number of behavioural and psychological symptoms including depression in children in primary school. ${ }^{8}$ Anxiety, a fear of going to school, feelings of being unsafe and unhappy at school, and low self esteem have all been reported to be consequences of repeatedly being bullied. ${ }^{2}{ }^{9}$ Depression has also been linked to being bullied. ${ }^{10}$

Being a bully in childhood and adolescence has been associated with delinquency in adulthood. Being bullied has been associated with poorer perceived health, depression, and with mental disorders in adulthood. ${ }^{11}$

The aim of this study was to investigate the association between bullying, depression, and severe suicidal ideation among adolescents aged 14-16 in Finland.

\section{Participants and methods}

The school health promotion study is a classroom survey focusing on adolescent health, health behaviour, and behaviour in school; it has been carried out annually in Finland every April since 1995. The health promotion study has been approved by the ethical committee of Tampere University Hospital.

In 1997, students in the 8th and 9th grades of secondary school (ages 14-16 years) in two regions in Finland (Vaasa and Pirkanmaa) participated in the study. Out of a total of 20213 pupils in these schools, 2570 (13\%) were absent on the day of the survey. Altogether, 17643 pupils $(87 \%)$ returned the questionnaire $(8695$ girls, 8948 boys). A total of 1179 students (6.7\%) gave incomplete responses on the Beck inventory and their questionnaires were excluded from the analysis. An additional 54 respondents did not answer the questions about bullying and were also excluded from the analysis. We were thus able to analyse the responses of 16410 students ( $81 \%$ of the target population, $93 \%$ of those present at school).

Involvement in bullying either as a bully or as the person being bullied was evaluated using two questions derived from a World Health Organisation study on youth health. ${ }^{12}$ The subject was introduced as follows:

The next questions are about bullying. We say a pupil is being bullied when another pupil, or a group of pupils, says or does nasty and unpleasant things to him or her. It is also bullying when a pupil is teased repeatedly in a way he or she 